\title{
Role of $B$ cell inhibitory receptor polymorphisms in systemic lupus erythematosus: a negative times a negative makes a positive
}

\author{
Naoyuki Tsuchiya $\cdot$ Zen-ichiro Honda \\ Katsushi Tokunaga
}

Received: 10 May 2006/ Accepted: 9 June 2006/ Published online: 1 September 2006

(C) The Japan Society of Human Genetics and Springer-Verlag 2006

\begin{abstract}
B lymphocytes play a pivotal role in the pathogenesis of systemic lupus erythematosus (SLE). Here, we will review our studies on the role of polymorphisms of two genes coding for B cell inhibitory receptors, $F C G R 2 B$ and $C D 72$. In FCGR2B, a single nucleotide polymorphism leading to a nonsynonymous substitution, Ile232Thr, within the transmembrane domain was identified, and a significant association of the 232Thr/Thr genotype with SLE was observed in Japanese, Thai and Chinese populations, while this allele was found to be rare in Caucasians. On the other hand, the association of $F C G R 2 B$ promoter polymorphism with SLE in Caucasians has been reported by two independent groups, but this allele was not found to be present in Japanese. These observations demonstrate that the association of FCGR $2 B$ polymorphisms with SLE is common to multiple populations, but the alleles associated with SLE depend upon the genetic background of each population. Functional analyses using a human B cell line lacking endogenous Fc $\gamma$ RIIb revealed that SLE-associated 232Thr allele product was partially excluded from membrane lipid rafts under resting conditions and after coligation with $\mathrm{B}$ cell receptor, and was significantly less potent at
\end{abstract}

N. Tsuchiya $(\bowtie) \cdot K$. Tokunaga

Department of Human Genetics,

Graduate School of Medicine,

The University of Tokyo, 7-3-1 Hongo Bunkyo-ku,

Tokyo 113-0033, Japan

e-mail: tsuchiya-tky@umin.net

Z. Honda

Department of Allergy and Rheumatology,

Graduate School of Medicine,

The University of Tokyo, Tokyo, Japan inhibiting B cell activation. Two haplotypes were identified in $C D 72$, one of which was associated with increased production of an alternative splicing isoform that substantially alters the extracellular region of CD72. Interestingly, the presence of the haplotype significantly decreased the risk of SLE conferred by FCGR2B-232Thr in an epistatic manner. These observations emphasize the need to understand human immune system diversity if we are to improve our understanding of the pathogenesis of autoimmune diseases.

Keywords Systemic lupus erythematosus .

Polymorphism $\cdot$ FCGR $2 B \cdot C D 72 \cdot$ Lipid raft ·

Alternative splicing $\cdot$ Epistasis $\cdot$ Inhibitory receptor

\section{Genetic background of systemic lupus erythematosus}

Systemic lupus erythematosus (SLE) is a prototype of systemic autoimmune diseases. Epidemiological data indicate that genetic factors play a substantial role in the disease, and intensive searches for susceptibility genes are underway by genome-wide as well as candidate gene approaches (Tsao 2004).

Genome-wide linkage analyses have been reported from five groups from North America and Europe. Collectively, more than 50 regions have been identified as meeting the suggestive level of linkage (LOD $\geq 1.9$ or $P<0.01$ ), including seven regions showing a significant level of linkage (LOD $\geq 3.3), 1 \mathrm{q} 22-23,1 \mathrm{q} 41-42,2 \mathrm{q} 37$, 4p16, 6p21-11, 16q13 and 17p13 (Kelly et al. 2002).

Studies on biological and positional candidate genes have reported a number of potential susceptibility genes. Among these, the HLA-DRB1 (DRB1*1501 in 
Asians and Caucasians, $D R B 1 * 1503$ in African-Americans and $D R B 1 * 0301$ in Caucasians) and $C 4 A * Q 0$ alleles, both located within the MHC complex at $6 \mathrm{p} 21.3$, are the most well-established. As we will see later, genes within the low affinity FCGR cluster at 1q23 (FCGR2A, $3 A, 3 B$ ) have frequently been reported to be associated with SLE, although the results are not very consistent; as is the case with mannose-binding lectin (10q11.2-12). $P D C D 1$, coding for an inhibitory receptor PD-1 on the $T$ cells, has been identified as being associated with SLE through a positional candidate approach (Prokunina et al. 2002). Recently, an association of IRF5 polymorphism was reported in northern European populations (Sigurdsson et al. 2005), and this has been convincingly replicated in a large-scale study of four cohorts (Sweden, Spain, Argentina and USA) (Graham et al. 2006), suggesting that IRF5 might be a susceptibility gene common to various populations.

We have been trying to identify susceptibility genes for rheumatic diseases through polymorphism screening and association studies of the functional genes in the immune system (Tsuchiya et al. 2002). The role of B lymphocytes in the pathogenesis of SLE has been established from a number of observations, such as the production of an array of autoantibodies and abnormalities in the peripheral blood B cell subsets, as well as a therapeutic effect of the $B$ cell-depleting anti$\mathrm{CD} 20$ monoclonal antibody (mAb) rituximab (Anolik and Sanz 2004); thus, genes coding for B cell regulatory molecules are considered to be strong candidates for susceptibility genes. Here, we will review a series of studies performed by us on the association of polymorphisms of two B cell inhibitory receptors with SLE.

\section{Detection of FCGR2B polymorphism in the transmembrane region and its association with SLE in Asian populations}

FCGR $2 B$ codes for a receptor for the Fc portion of $\operatorname{IgG}$ expressed on B cells and monocytes, $\mathrm{Fc} \gamma$ receptor $\mathrm{IIb}$ (Fc $\gamma$ RIIb). Fc $\gamma$ RIIb contains immunoreceptor tyrosinebased inhibitory motif (ITIM) in its cytoplasmic region, which becomes phosphorylated when Fcy RIIb is coligated with $\mathrm{B}$ cell receptor (BCR) by antigen-IgG complexes and recruits SH2-containing 5'-inositolphosphate phosphatase (SHIP). SHIP hydrolyzes phosphatidylinositol-3,4,5-triphosphate (PIP3) and attenuates activation and survival signals in B cells (Takai 2002). Thus, Fc $\gamma$ RIIb represents one of the molecules that prevents excessive B cell activation.

Indeed, $F c g r 2 b$-deficient mice become susceptible to autoimmune diseases such as collagen-induced arthritis
(Yuasa et al. 1999) and Goodpasture's syndrome (Nakamura et al. 2000). Moreover, depending on their genetic backgrounds, they spontaneously develop lupus-like disease (Bolland and Ravetch 2000; Yajima et al. 2003) with the production of rheumatoid factor and anti-DNA antibody (Moll et al. 2004). Such mice exhibit an increased frequency of anti-DNA antibodyproducing plasma cells, suggesting a role of Fc $\gamma$ RIIb in the maintenance of peripheral tolerance (Fukuyama et al. 2005). Furthermore, mice strains which spontaneously develop lupus or autoimmune disease, such as NZB, MRL and NOD, all share Fcgr $2 b$ polymorphisms (Jiang et al. 1999, 2000), and the development of autoimmunity is inhibited in such mice by the transfer of the wild-type $F c g r 2 b$ gene (McGaha et al. 2005).

Human FCGR2B gene and other classical FCGR genes such as FCGR2A, $2 C, 3 A$ and $3 B$ form a gene family clustered within $\sim 200-\mathrm{kb}$ of 1q23 (Su et al. 2002). These genes, which are presumed to have developed through unequal crossover events, are extremely homologous to one another, not only in exons but also in introns and intergenic regions.

Association with $F C G R 2 A, 3 A$ and $3 B$ polymorphisms as well as linkage to this region has been reported on multiple occasions (Hatta et al. 1999; Tsuchiya and Kyogoku 2005). Unlike FCGR2B, $F C G R 2 A, 3 A$ and $3 B$ mediate activation signals and phagocytosis in cell lineages such as neutrophils, monocytes and NK cells. All of these genes have functional polymorphisms, and, interestingly, alleles that are reported to be associated with SLE at each locus (FCGR2A-131Arg, FCGR3A-176Phe [also referred to as $158 \mathrm{Phe}$ ], FCGR3B-NA2) uniformly exhibit lower affinity to $\mathrm{IgG}$ or decreased phagocytotic potential compared with the nonassociated alleles. The mechanism of association has been explained by defective clearance of the immune complex (Dijstelbloem et al. 2001). However, prior to our studies, linkage disequilibrium (LD) among these genes and FCGR2B had not been investigated; therefore, the possibility that FCGR2B might be the causative susceptibility gene that explains the linkage and association signals of this region had not been formally excluded.

Based on such a background, FCGR2B was considered a strong candidate susceptibility gene to SLE. However, polymorphism screening of $F C G R 2 B$ proved to be extremely difficult because the nucleotide sequence of $F C G R 2 B$ was almost identical to FCGR2C from the $5^{\prime}$ flanking region to exon 6 , in terms of both exons and in introns, and the specific amplification of $F C G R 2 B$ was not successful. Furthermore, some of the single nucleotide differences between FCGR2B and $2 C$ found in the database turned out to be polymorphisms. 
We employed nested PCR to specifically amplify the FCGR $2 B$ gene, and identified a single nucleotide polymorphism (SNP) (c.695T $>C$, rs1050501) which led to an amino acid substitution within the transmembrane domain at position 232, Ile232Thr (Kyogoku et al. 2002). (The same SNP is also referred to as Ile187Thr by excluding the signal sequence; $\mathrm{Li}$ et al. 2003.) A case-control association study on Japanese indicated that there was a significant association of the 232Thr/Thr genotype with SLE (Kyogoku et al. 2002). We subsequently replicated the association of this polymorphism with SLE in Thai (Siriboonrit et al. 2003) and Chinese populations (Chu et al. 2004). When the data from these three Asian populations were combined using meta-analysis, the odds ratio of 232Thr/Thr for developing SLE was 2.45 (95\% confidence interval 1.49-4.02, $P=0.0004$ ) against 232Ile/Ile genotype (Table 1a). This association was predominantly observed in the patients with lupus nephritis (Chu et al. 2004).

$F C G R 2 B$ was found to be in LD with FCGR $3 B, 3 A$ and $2 A$. In Asian subjects, association with SLE was also found for $F C G R 3 B$-NA2 and $3 A-176 \mathrm{Phe}$. The association of each of the three FCGRs could not be explained solely by LD with other FCGR; thus, each of the FCGRs appeared to have its own contribution (Kyogoku et al. 2002; Chu et al. 2004).

\section{Population difference}

It is becoming increasingly clear that susceptibility genes are often different among populations. For example, the association of PTPN22-Arg620Trp with rheumatoid arthritis (RA) has now been replicated in multiple Caucasian populations (Gregersen and Batliwalla 2005), but this allele is not found in Japanese (Mori et al. 2005).

Although the results are not consistent, many studies have demonstrated associations of FCGR2A, $3 A$ and $3 B$ with SLE. Recent meta-analyses have demonstrated that FCGR2A is associated with the development of SLE (Karassa et al. 2002), while FCGR3A is associated with the presence of nephritis (Karassa et al. 2003). These meta-analyses are mostly based on data from Caucasian populations. As described above, we observed associations of FCGR3A and $3 B$ (in addition to $F C G R 2 B$ ) in three Asian populations, but not an association of $2 A$ (Chu et al. 2004). This difference was not caused by differences in the genotyping methods, because we observed an association of $F C G R 2 A$, but not $3 A$, with SLE in Caucasians (Kyogoku et al. 2004). Thus, this differ- ence seems to be caused by differences by the populations.

As for FCGR2B, association with FCGR2B-232Thr was found in three Asian populations. However, this allele was rare in Caucasians, and significant association with SLE was not detected ( $\mathrm{Li}$ et al. 2003; Kyogoku et al. 2004; Magnusson et al. 2004) (Table 1a).

On the other hand, two groups demonstrated an association of $F C G R 2 B$ promoter polymorphisms in Caucasians (Su et al. 2004a; Blank et al. 2005). However, this promoter allele was not found in Japanese (unpublished results). This might be another example of a difference between populations, but it also may represent an allelic heterogeneity between populations (Table 1b). The finding that two different polymorphic sites of the same gene are associated with the same disease in different populations may provide strong evidence to support the role of the gene in the disease. Differences between the alleles associated with SLE among populations have also been reported in PDCD1. While the A allele at an intron 4 SNP called PD1.3 has been shown to be significantly increased among Swedish, European American and Mexican patients (Prokunina et al. 2002), the same allele was significantly decreased in Spanish SLE (Ferreiros-Vidal et al. 2004).

The two groups reported conflicting results regarding the activity of the SLE-associated promoter allele. While Su et al. (2004a, 2004b) reported a SLE-associated promoter haplotype containing the $-386 \mathrm{C}$ allele (rs3219018), Blank et al. (2005) reported a lower promoter activity for the $-386 \mathrm{C}$ allele (they referred to the same SNP as $-343 \mathrm{G}>\mathrm{C}$ by counting from the transcription start site). This discrepancy may be caused by differences between the experimental systems used, although lower promoter activity is in better agreement with other lines of evidence, including our own, as described later.

A copy number polymorphism (CNP) is known to exist for FCGR3B. In addition to the common haplotype carrying one $F C G R 3 B$ locus, haplotypes carrying no or two FCGR3B loci are present. Thus, the number of $F C G R 3 B$ loci in each individual varies from 0 to 4 . FCGR3B CNP appears to be common in Caucasians, and it was recently reported that low copy number of $F C G R 3 B$ is associated with the presence of nephritis in SLE in the northern European population (Aitman et al. 2006). Detection of FCGR3B CNP is technically challenging, and population data are not available for other populations. However, we found that homozygosity of the reduction-of-function allele NA2 is associated with nephritis in SLE in Asians (Chu et al. 2004), supporting the idea that a reduction of function 


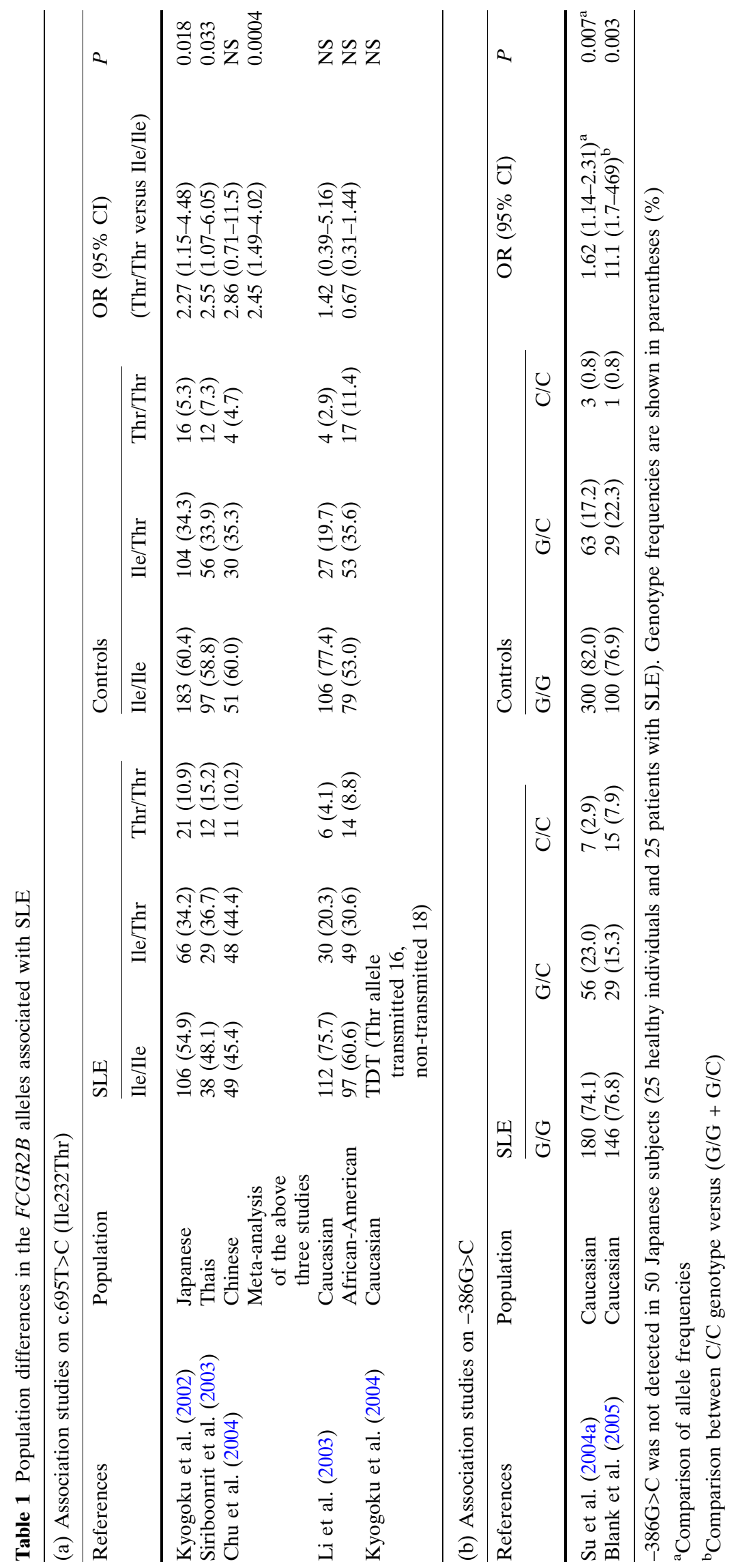


for Fc $\gamma$ RIIIb is somehow associated with development of nephritis.

\section{$F C G R 2 B-232 T h r$ is a reduction-of-function inhibitory receptor}

Since homozygous deletion of FCGR2B in mice has been repeatedly shown to be susceptible to autoimmune diseases (Takai 2002; Nimmerjahn and Ravetch 2006), functional difference between the polymorphic $F C G R 2 B$ allele products was the next focus of interest. Human Fc $\gamma$ RIIb exists in two isoforms, Fc $\gamma$ RIIb- 1 and $\mathrm{b}-2$, and in the latter, the first cytoplasmic exon that inhibits receptor internalization is spliced out. It is generally accepted that the b- 1 isoform is expressed in $\mathrm{B}$ cells, and the b-2 isoform in myeloid cell lineage including dendritic cells (Daeron 1997). Recent works highlighted the critical role of Fc $\gamma$ RIIb in B cells in preventing tolerance breakdown, based on the observations that retroviral Fc $\gamma$ RIIb gene transfer to B cells effectively suppresses autoimmunity associated with reduced Fc $\gamma$ RIIb expression in NZB, MRL and NOD mice (McGaha et al. 2005).

In order to characterize the polymorphic human $F C G R 2 B$ allele products in the context of $\mathrm{B}$ cells, we took advantage of the ST486 human B cell line, which is inherently devoid of Fc $\gamma \mathrm{RIIb}$ expression (Koncz et al. 1998). The IIA1.6 subline of mouse A20 cells, which also lacks Fc $\gamma$ RIIb, has so far been utilized as a competent cell line. However, IIA1.6 is obviously inappropriate in this setting for studying Ile232Thr single amino acid substitution, in light of the modest amino acid identity ( $\sim 60 \%)$ of human and mouse Fc $\gamma$ RIIb. Indeed, a recent functional analysis of the polymorphic Fc $\gamma$ RIIb in IIA1.6 (Li et al. 2003) has led to different conclusions from ours using ST486 human B cells (Kono et al. 2005), and also from those using human macrophages (Floto et al. 2005).

Each allele of the human Fc $\gamma$ RIIb-1 isoform was introduced into ST486 cells, and two groups of cells with equivalent Fc $\gamma$ RIIb-1 expression were established. First we determined ligand-binding parameters. The results showed that the dissociation constants of human Fc $\gamma$ RIIb for $\operatorname{IgG}$ are in the order of $10^{-7} \mathrm{M}$, values comparable with those in the previous studies (Nimmerjahn and Ravetch 2006), and that Ile232Thr substitution does not significantly affect the binding affinity.

Recent analysis of receptor-proximal events in a variety of systems has featured a novel view of initial signaling that involves specialized plasma membrane domains, variously referred to as lipid rafts, detergent- insoluble membrane domains (DRMs) or detergentinsensitive membranes (DIMs) (Simons and Ikonen 1997; Ikonen 2001; London 2002). Lipid rafts are small membrane patches (diameter $<100 \mathrm{~nm}$ ) consisting of a plasma membrane bilayer and constructed with specific lipids including cholesterol and glycosphingolipid. Lipid rafts accumulate receptor-proximal signaling molecules harboring saturated acyl-chain anchors, including Src family kinases, heterotrimeric G proteins and adaptor proteins such as linker for activation of $\mathrm{T}$ cells (LAT) and C-terminal Src kinase (Csk) binding protein (Cbp) (Pierce 2002). Receptors such as T and B cell receptors, Fc receptors and TNF family receptors become associated with, or induce the aggregation of, lipid rafts shortly after agonist addition (Fig. 1). It is convincingly argued that this process precedes tyrosine phosphorylation signaling, and, moreover, is required for the de novo generation of signaling (Honda et al. 2000; Suzuki et al. 2000; Kono et al. 2002; Pierce 2002). Since we have unveiled the critical roles of their transmembrane domains in the association of Fc receptor with lipid rafts (Kono et al. 2002), we hypothesized that Ile232Thr substitution influences Fc $\gamma$ RIIb redistribution to lipid rafts.

Distribution of receptor to lipid rafts is best measured by the surface probing of the receptor with specific antibody Fab labeled with ${ }^{125}$ I, followed by its solubilization with nonionic detergents and fractionation under density gradient ultracentrifugation (Field et al. 1997; Holowka et al. 2000). However, we found that it was impossible to prepare anti-human Fc $\gamma$ RIIb Fab with sufficient affinity for the analysis from the available FLI8.26 and AT-10 mAbs. We thus employed two different strategies to perform the assay (Kono et al. 2005). First, we created chimeric Fc $\gamma$ RIIbs in which extracellular domain of mouse FcrRIIb was fused to transmembrane (containing 232Ile or Thr) and

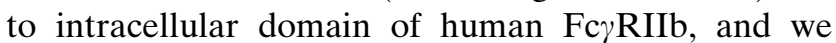
probed this with high affinity ${ }^{125} \mathrm{I}-2.4 \mathrm{G} 2 \mathrm{mAb}$ Fab. Second, human Fc $\gamma$ RIIb was probed with ${ }^{125}$ I-AT10 whole IgG. Both systems yielded consistent results; $232 \mathrm{Thr}$ was relatively excluded from lipid rafts as compared to 232Ile under resting conditions and after coligation with BCR, and the differences were statistically significant (Kono et al. 2005).

It is widely accepted that Fc $\gamma$ RIIb is able to attenuate BCR signaling only when it is physically coligated with BCR (Muta et al. 1994; Ravetch and Lanier 2000). These features are different from the other B cell inhibitory coreceptors $\mathrm{CD} 22$ and $\mathrm{CD} 72$, which also possess ITIM: CD22 and CD72 are able to suppress BCR signaling without coligation (Adachi et al. 2000; Nitschke and Tsubata 2004). Although this concept is 
supported by several series of reports, it may be worth bearing in mind that this idea derives from the observations in mouse B cells. In the current study, it was reproducibly observed that human $\mathrm{Fc} \gamma \mathrm{RIIb}$ attenuates BCR signaling in ST486 immortalized human B cells even when BCR was ligated separately from Fc $\gamma$ RIIb (Kono et al. 2005).

With respect to the allelic differences, we found that the extent of either constitutive or coligation-induced inhibition was significantly greater in 232Ile than that in $232 \mathrm{Thr}$ by monitoring a variety of signals including phosphatidylinositol 3,4,5-trisphosphate (PIP3) levels, phospholipase $\mathrm{C} \gamma 2$ (PLC $\gamma 2)$ and Akt tyrosine phosphorylation and calcium mobilization (Kono et al. 2005). From the functional aspects, therefore, it was concluded that human Fc $\gamma$ RIIb 232Thr represents a reduction-of-function receptor isoform when taking 232Ile as a standard. This conclusion was supported by Floto et al. (2005), who showed that Fc $\gamma$ RIIb 232Ile exerts greater inhibitory effects than $232 \mathrm{Thr}$ in human macrophages on Fc $\gamma$ RI- and Fc $\gamma$ RIII-mediated phagocytosis, superoxide generation, cytokine production and MHC class I and II expression. In addition, it should be noted that, under the experimental conditions of Floto et al., Fc $\gamma$ RIIb was not coligated with Fc $\gamma$ RI. These findings indicate common mechanisms underlying constitutive inhibition by Fc $\gamma$ RIIb in human B cells and macrophages.

Does the altered subcellular distribution of $232 \mathrm{Thr}$, the partial exclusion from lipid rafts, provide a mechanistic basis for its phenotype? Floto et al. (2005) coincidentally showed defective $232 \mathrm{Thr}$ distribution to lipid rafts, and concluded it to be responsible for the loss-of-function characteristics of $232 \mathrm{Thr}$. It is certainly attractive to speculate that $232 \mathrm{Thr}$ is excluded from lipid rafts, and concurrently from BCR signaling complex (Fig. 1). However, it should be emphasized that no firm evidence exists in support of the idea that association with lipid rafts is a prerequisite for human Fc $\gamma$ RIIb to inhibit signaling from BCR or activating Fc $\gamma$ Rs. Indeed, Fas-mediated apoptosis has been shown to depend upon its association with lipid rafts in certain cell types (type I cells), but not in others (type II cells) (Muppidi and Siegel 2004). The determinant in the transmembrane structure required for Fc $\gamma$ RIIB to associate with lipid rafts, and to efficiently attenuate BCR signaling needs to be elucidated in future studies.

\section{Polymorphisms affecting the alternative splicing of $\mathrm{CD72}$}

CD72 is a $45 \mathrm{kDa}$ type II transmembrane protein containing a C-type lectin domain expressed in B cells, dendritic cells and macrophages as a homodimer. CD72 contains two ITIMs in its cytoplasmic tail, one of which recruits $\mathrm{SH} 2$-containing tyrosine phosphatase (SHP)-1, and functions as a negative regulator of BCR signaling (Adachi et al. 2000; Hokazono et al. 2003; Nitschke and Tsubata 2004).

Human CD72 gene is encoded on human chromosome 9p13.2. In a murine model of SLE, MRL/lpr,
Fig. 1 Schematic hypothetical representation of the Fc $\gamma$ RIIb-232Ile redistribution to lipid rafts (upper panel) and 232Thr exclusion from lipid rafts (lower panel). Note that, even if $232 \mathrm{Thr}$ is (partially) excluded from lipid rafts, this does not necessarily mean that $232 \mathrm{Thr}$ is concomitantly excluded from $\mathrm{B}$ cell receptor $(B C R)$ signaling machinery.

IC immune complex
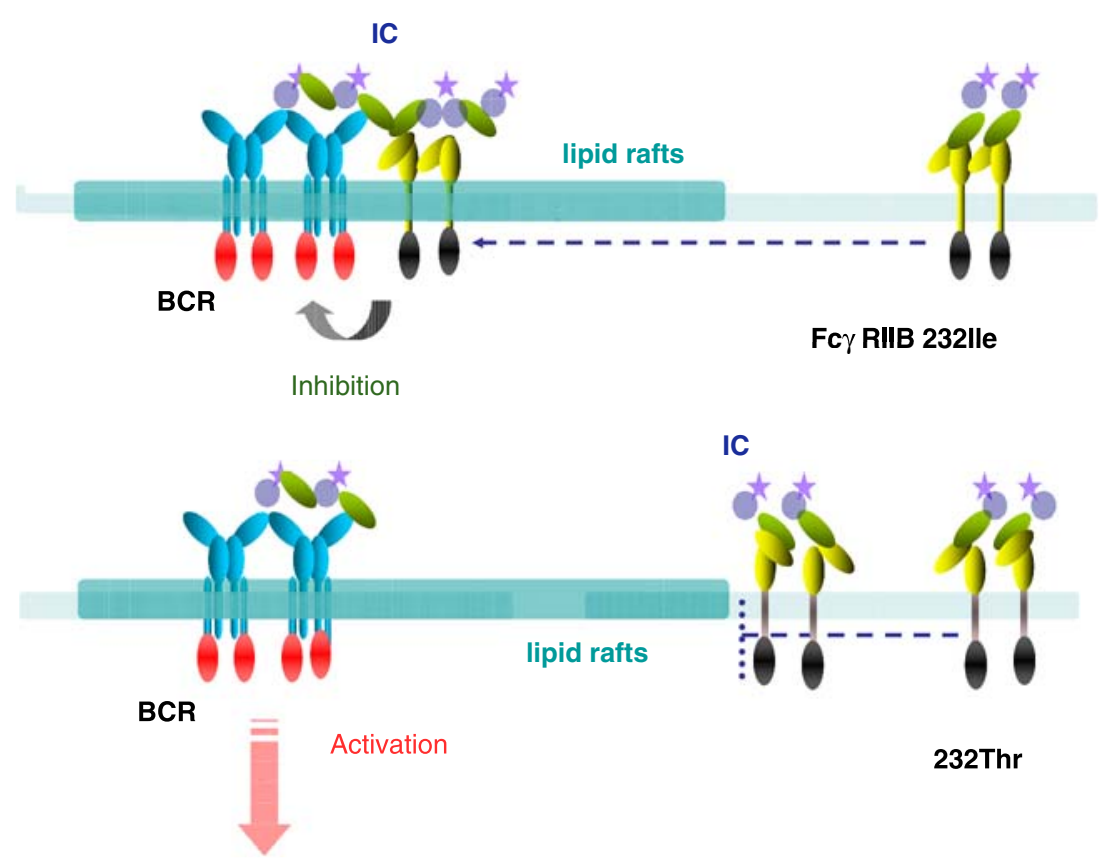
$C D 72 c$ allele has been shown to be associated with systemic vasculitis phenotype ( $\mathrm{Qu}$ et al. 2000), indicating that $C D 72$ accounts for one of the background genes of MRL.

Based on such information, we considered $C D 72$ as a candidate susceptibility gene for human SLE. Polymorphism screening revealed four polymorphic sites with minor allele frequencies $>0.01$, two of which were 13-nucleotide repeat polymorphism (once or twice) and four-nucleotide deletion in intron 8. These four polymorphic sites were in $\mathrm{LD}$, forming two major haplotypes. The haplotypes were represented by the number of the 13-nucleotide repeat used as the tag polymorphism (*1 and *2) (Hitomi et al. 2004).

A case-control association study did not show significant association with the development of SLE; however, genotype $* 1 / * 1$ was increased and $* 2 / * 2$ was decreased in the SLE patients with nephritis. Furthermore, when the combination of the FCGR2B and $C D 72$ genotypes was examined in the Japanese and Thai populations, it was revealed that the association of $F C G R 2 B-232 \mathrm{Thr} / \mathrm{Thr}$ with SLE was more striking in individuals with $C D 72-* 1 / * 1$ genotype $(P=0.009)$, while the risk of this $F C G R 2 B$ genotype was substantially decreased and did not reach statistical significance in individuals with $C D 72-* 1 / * 2$ and $* 2 / * 2$ genotypes (Hitomi et al. 2004) (Fig. 2). Thus, CD72 polymorphisms were shown to affect the risk of FCGR2B polymorphisms for SLE, although $C D 72$ per se had only a slight effect, if any, on the development of SLE. It is interesting to note that $F C G 2 B-232 \mathrm{Thr} / \mathrm{Thr}$ also showed a preferential association in the subgroup of SLE with nephritis (Chu et al. 2004), suggesting that genetic interaction with $C D 72$ may play a role.

In view of the two polymorphic sites within intron 8 , we then examined whether the polymorphisms influence splicing. RT-PCR of RNA derived from peripheral blood mononuclear cells using primers placed within exons 6 and 9 revealed two amplification products, one of which was found to encode a novel alternative splicing isoform caused by exon 8 skipping (AS isoform). While the termination codon appears within exon 8 in the common isoform, exon 8 is skipped in the AS isoform. This would result in the translation of exon 9 sequences until the new termination codon appears, leading to the replacement of 42 C-terminal amino acids in the membrane-distal portion of the extracellular region with 49 new amino acids in the AS form. The predicted amino acid sequence maintains the C-type lectin domain, suggesting that the alternative isoform may be functional at the protein level. Indeed, we confirmed that the protein product of this isoform is expressed when the full- length cDNA is introduced into the COS-7 cells (Hitomi et al. 2004).

We then examined whether the polymorphisms affect the efficiency of alternative splicing, and this was indeed found to be the case. Thus, although both common and AS isoforms were found in each individual, the proportion of AS isoform was clearly increased in individuals with $* 2 / * 2$ genotype, followed by $* 1 / * 2$. We confirmed that the 13 -nucleotide repeat and four-nucleotide deletion directly regulate the splicing efficiency by minigene assay (Hitomi et al. 2004).

These results imply that the $C D 72-* 2$ allele increases the relative proportion of the $C D 72$ AS isoform, and protects its carriers from the risk of SLE conferred by the FCGR2B-232Thr/Thr genotype. The molecular mechanisms of this protection are currently being investigated.

\section{Concluding remarks}

It is surprising that our studies that focused on two genes provided potential keys to so many new fields of biological significance, such as the relationships between transmembrane polymorphism, lipid raft and signaling, as well as genomic polymorphism, alternative splicing and epistatic interaction.

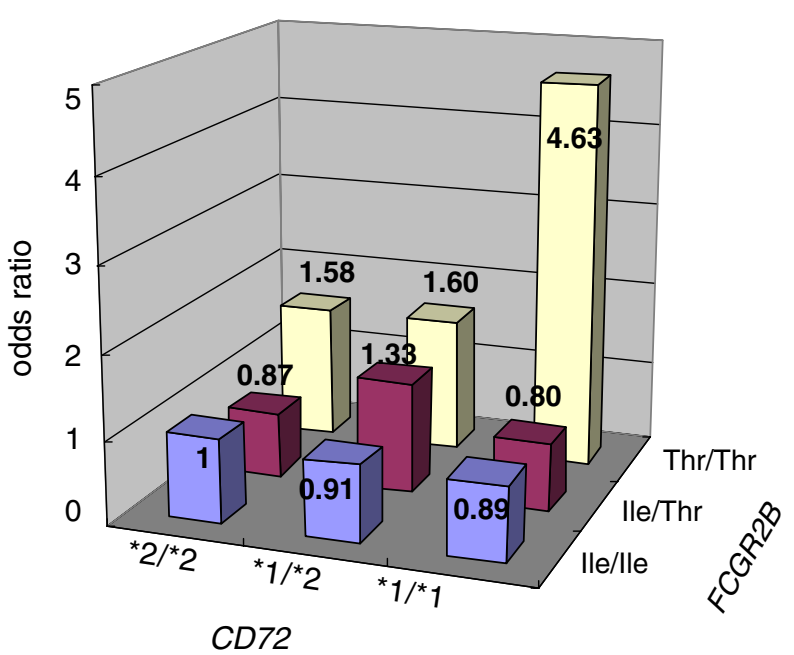

Fig. 2 Genetic interaction between $F C G R 2 B$ and $C D 72$ polymorphisms against the development of SLE. Risk of SLE conferred by $F C G R 2 B-232 \mathrm{Thr} / \mathrm{Thr}$ genotype only reached statistical significance in individuals with $C D 72-* 1 / * 1$ $(P=0.009)$, not in individuals with $C D 72-* 1 / * 2$ and $* 2 / * 2$ genotypes. The odds ratios for the FCGR2B genotype alone were 2.38 (232Thr/Thr) and 1.10 (232Ile/Thr) versus 232Ile/Ile, and those for $C D 72$ alone were $1.07(* 1 / * 1), 1.18(* 1 / * 2)$ versus $* 2 / * 2$. The data were derived from Japanese and Thai association studies combined via meta-analysis (Hitomi et al. 2004) 
Human systems are much more complicated than we could possibly imagine, and immune systems are already known to be highly polymorphic, with most genes being subject to alternative splicing (Lynch 2004). Most of our current understanding of the immune system is based on the analysis of the interaction among the major isoform of the major allele of each gene. Although such analysis provides an indispensable scheme for the molecular interaction, in order to fully understand the diversity of immune responses among human populations, and the etiology and pathogenesis of human disease, it will be necessary to study multiple isoforms and alleles of each gene and their interactions as well.

Acknowledgments The authors wish to thank many collaborators involved in our studies and cited in this review, especially Dr. Chieko Kyogoku (Department of Human Genetics, The University of Tokyo; Center for Immunology, University of Minnesota), Dr. Hajime Kono (Department of Allergy and Rheumatology, The University of Tokyo; Department of Pathology, University of Massachusetts), Yuki Hitomi and Aya Kawasaki (Department of Human Genetics, The University of Tokyo). This study was supported by grants from the Ministry of Education, Culture, Sports, Science and Technology (MEXT) of Japan, the Ministry of Health, Labour, and Welfare of Japan and Japan Society for the Promotion of Science (JSPS).

\section{References}

Adachi T, Wakabayashi C, Nakayama T, Yakura H, Tsubata T (2000) CD72 negatively regulates signaling through the antigen receptor of B cells. J Immunol 164:1223-1229

Aitman TJ, Dong R, Vyse TJ, Norsworthy PJ, Johnson MD, Smith J, Mangion J, Roberton-Lowe C, Marshall AJ, Petretto E, Hodges MD, Bhangal G, Patel SG, Sheehan-Rooney K, Duda M, Cook PR, Evans DJ, Domin J, Flint J, Boyle JJ, Pusey CD, Cook HT (2006) Copy number polymorphism in Fcgr3 predisposes to glomerulonephritis in rats and humans. Nature 439:851-855

Anolik J, Sanz I (2004) B cells in human and murine systemic lupus erythematosus. Currr Opin Rheumatol 16:505-512

Blank MC, Stefanescu RN, Masuda E, Marti F, King PD, Redecha PB, Wurzburger RJ, Peterson MG, Tanaka S, Pricop L (2005) Decreased transcription of the human FCGR2B gene mediated by the $-343 \mathrm{G} / \mathrm{C}$ promoter polymorphism and association with systemic lupus erythematosus. Hum Genet 117:220-227

Bolland S, Ravetch JV (2000) Spontaneous autoimmune disease in Fc $\gamma$ RIIB-deficient mice results from strain-specific epistasis. Immunity 13:277-285

Chu ZT, Tsuchiya N, Kyogoku C, Ohashi J, Qian YP, Xu SB, Mao CZ, Chu JY, Tokunaga K (2004) Association of Fc $\gamma$ receptor IIb polymorphism with susceptibility to systemic lupus erythematosus in Chinese: a common susceptibility gene in the Asian populations. Tissue Antigens 63:21-27

Daeron M (1997) Fc receptor biology. Annu Rev Immunol 15:203-234

Dijstelbloem HM, van de Winkel JG, Kallenberg CG (2001) Inflammation in autoimmunity: receptors for $\mathrm{IgG}$ revisited. Trends Immunol 22:510-516
Ferreiros-Vidal I, Gomez-Reino JJ, BarrosF, Carracedo A, Carreira P, Gonzalez-Escribano F, Liz M, Martin J, Ordi J, Vicario JL, Gonzalez A (2004) Association of PDCD1 with susceptibility to systemic lupus erythematosus. Evidence of population-specific effects. Arthritis Rheum 50:2590-2597

Field KA, Holowka D, Baird B (1997) Compartmentalized activation of the high affinity immunoglobulin $\mathrm{E}$ receptor within membrane domains. J Biol Chem 272:4276-4280

Floto RA, Clatworthy MR, Heilbronn KR, Rosner DR, MacAry PA, Rankin A, Lehner PJ, Ouwehand WH, Allen JM, Watkins NA, Smith KG (2005) Loss of function of a lupusassociated Fc $\gamma$ RIIb polymorphism through exclusion from lipid rafts. Nat Med 11:1056-1058

Fukuyama H, Nimmerjahn F, Ravetch JV (2005) The inhibitory $\mathrm{Fc} \gamma$ receptor modulates autoimmunity by limiting the accumulation of immunoglobulin $\mathrm{G}+$ anti-DNA plasma cells. Nat Immunol 6:99-106

Graham RR, Kozyrev SV, Baechler EC, Reddy MV, Plenge RM, Bauer JW, Ortmann WA, Koeuth T, Escribano MF, Collaborative Groups TA, Pons-Estel B, Petri M, Daly M, Gregersen PK, Martin J, Altshuler D, Behrens TW, Alarcón-Riquelme ME (2006) A common haplotype of interferon regulatory factor 5 (IRF5) regulates splicing and expression and is associated with increased risk of systemic lupus erythematosus. Nat Genet 38:550-555

Gregersen PK, Batliwalla F (2005) PTPN22 and rheumatoid arthritis: gratifying replication. Arthritis Rheum 52:1952-1955

Hatta Y, Tsuchiya N, Ohashi J, Matsushita M, Fujiwara K, Hagiwara K, Juji T, Tokunaga K (1999) Association of Fc $\gamma$ receptor IIIB, but not of Fc $\gamma$ receptor IIA and IIIA polymorphisms with systemic lupus erythematosus in Japanese. Genes Immun 1:53-60

Hitomi Y, Tsuchiya N, Kawasaki A, Ohashi J, Suzuki T, Kyogoku C, Fukazawa T, Bejrachandra S, Siriboonrit U, Chandanayingyong D, Suthipinittharm P, Tsao BP, Hashimoto H, Honda Z, Tokunaga K (2004) CD72 polymorphisms associated with alternative splicing modify susceptibility to human systemic lupus erythematosus through epistatic interaction with FCGR2B. Hum Mol Genet 13:2907-2917

Hokazono Y, Adachi T, Wabl M, Tada N, Amagasa T, Tsubata $\mathrm{T}$ (2003) Inhibitory coreceptors activated by antigens but not by anti-Ig heavy chain antibodies install requirement of costimulation through CD40 for survival and proliferation of B cells. J Immunol 171:1835-1843

Holowka D, Sheets ED, Baird B (2000) Interactions between Fc $\epsilon$ RI and lipid raft components are regulated by the actin cytoskeleton. J Cell Sci 113:1009-1019

Honda Z, Suzuki T, Kono H, Okada M, Yamamoto T, Ra C, Morita Y, Yamamoto K (2000) Sequential requirements of the N-terminal palmitoylation site and $\mathrm{SH} 2$ domain of Src family kinases in the initiation and progression of $\mathrm{Fc} \epsilon \mathrm{RI}$ signaling. Mol Cell Biol 20:1759-1771

Ikonen E (2001) Roles of lipid rafts in membrane transport. Curr Opin Cell Biol 13:470-477

Jiang Y, Hirose S, Sanokawa-Akakura R, Abe M, Mi X, Li N, Miura Y, Shirai J, Zhang D, Hamano Y, Shirai T (1999) Genetically determined aberrant down-regulation of FcgammaRIIB1 in germinal center B cells associated with hyper- $\operatorname{IgG}$ and $\mathrm{IgG}$ autoantibodies in murine systemic lupus erythematosus. Int Immunol 11:1685-1691

Jiang Y, Hirose S, Abe M, Sanokawa-Akakura R, Ohtsuji M, Mi X, Li N, Xiu Y, Zhang D, Shirai J, Hamano Y, Fujii H, Shirai T (2000) Polymorphisms in IgG Fc receptor IIB regulatory regions associated with autoimmune susceptibility. Immunogenetics 51:429-435 
Karassa FB, Trikalinos TA, Ioannidis JP (2002) Role of the Fcy receptor IIa polymorphism in susceptibility to systemic lupus erythematosus and lupus nephritis: a meta-analysis. Arthritis Rheum 46:1563-1571

Karassa FB, Trikalinos TA, Ioannidis JP (2003) The Fc $\gamma$ RIIIAF158 allele is a risk factor for the development of lupus nephritis: a meta-analysis. Kidney Int 63:1475-1482

Kelly JA, Moser KL, Harley JB (2002) The genetics of systemic lupus erythematosus: putting the pieces together. Genes Immun 3(Suppl 1):S71-S85

Koncz G, Gergely J, Sarmay G (1998) Fc $\gamma$ RIIb inhibits both B cell receptor- and $\mathrm{CD} 19$-induced $\mathrm{Ca}^{2+}$ mobilization in $\mathrm{F} c \gamma \mathrm{R}$-transfected human B cells. Int Immunol 10:141146

Kono H, Suzuki T, Yamamoto K, Okada M, Yamamoto T, Honda Z (2002) Spatial raft coalescence represents an initial step in Fc $\gamma$ R signaling. J Immunol 169:193-203

Kono H, Kyogoku C, Suzuki T, Tsuchiya N, Honda H, Yamamoto K, Tokunaga K, Honda Z (2005) Fc $\gamma$ RIIB Ile232Thr transmembrane polymorphism associated with human systemic lupus erythematosus decreases affinity to lipid rafts and attenuates inhibitory effects on B cell receptor signaling. Hum Mol Genet 14:2881-2892

Kyogoku C, Dijstelbloem HM, Tsuchiya N, Hatta Y, Kato H, Yamaguchi A, Fukazawa T, Jansen MD, Hashimoto H, van de Winkel JG, Kallenberg CG, Tokunaga K (2002) Fc $\gamma$ receptor gene polymorphisms in Japanese patients with systemic lupus erythematosus: contribution of $F C G R 2 B$ to genetic susceptibility. Arthritis Rheum 46:1242-1254

Kyogoku C, Tsuchiya N, Wu H, Tsao BP, Tokunaga K (2004) Association of Fcrreceptor IIA, but not IIB and IIIA, polymorphisms with systemic lupus erythematosus: a familybased association study in Caucasians. Arthritis Rheum 50:671-673

Li X, Wu J, Carter RH, Edberg JC, Su K, Cooper GS, Kimberly RP (2003) A novel polymorphism in the Fc $\gamma$ receptor IIB (CD32B) transmembrane region alters receptor signaling. Arthritis Rheum 48:3242-3252

London E (2002) Insights into lipid raft structure and formation from experiments in model membranes. Curr Opin Struct Biol 12:480-486

Lynch KW (2004) Consequences of regulated pre-mRNA splicing in the immune system. Nat Rev Immunol 4:931940

Magnusson V, Zunec R, Odeberg J, Sturfelt G, Truedsson L, Gunnarsson I, Alarcon-Riquelme ME (2004) Polymorphisms of the Fc $\gamma$ receptor type IIB gene are not associated with systemic lupus erythematosus in the Swedish population. Arthritis Rheum 50:1348-1350

McGaha TL, Sorrentino B, Ravetch JV (2005) Restoration of tolerance in lupus by targeted inhibitory receptor expression. Science 307:590-593

Moll T, Nitschke L, Carroll M, Ravetch JV, Izui S (2004) A critical role for Fc $\gamma$ RIIB in the induction of rheumatoid factors. J Immunol 173:4724-4728

Mori M, Yamada R, Kobayashi K, Kawaida R, Yamamoto K (2005) Ethnic differences in allele frequency of autoimmune-disease-associated SNPs. J Hum Genet 50:264-266

Muppidi JR, Siegel RM (2004) Ligand-independent redistribution of Fas (CD95) into lipid rafts mediates clonotypic T cell death. Nat Immunol 5:182-189

Muta T, Kurosaki T, Misulovin Z, Sanchez M, Nussenzweig MC, Ravetch JV (1994) A 13-amino-acid motif in the cytoplasmic domain of Fc $\gamma$ RIIB modulates B-cell receptor signalling. Nature 368:70-73
Nakamura A, Yuasa T, Ujike A, Ono M, Nukiwa T, Ravetch JV, Takai T (2000) Fc $\gamma$ receptor IIB-deficient mice develop Goodpasture's syndrome upon immunization with type IV collagen: a novel murine model for autoimmune glomerular basement membrane disease. J Exp Med 191:899-906

Nimmerjahn F, Ravetch JV (2006) Fc $\gamma$ receptors: old friends and new family members. Immunity 24:19-28

Nitschke L, Tsubata T (2004) Molecular interactions regulate BCR signal inhibition by CD22 and CD72. Trends Immunol 25:543-550

Pierce SK (2002) Lipid rafts and B-cell activation. Nat Rev Immunol 2:96-105

Prokunina L, Castillejo-Lopez C, Oberg F, Gunnarsson I, Berg L, Magnusson V, Brookes AJ, Tentler D, Kristjansdottir H, Grondal G, Bolstad AI, Svenungsson E, Lundberg I, Sturfelt G, Jonssen A, Truedsson L, Lima G, Alcocer-Varela J, Jonsson R, Gyllensten UB, Harley JB, Alarcon-Segovia D, Steinsson $\mathrm{K}$, Alarcon-Riquelme ME (2002) A regulatory polymorphism in $P D C D 1$ is associated with susceptibility to systemic lupus erythematosus in humans. Nat Genet 32:666-669

Qu WM, Miyazaki T, Terada M, Lu LM, Nishihara M, Yamada A, Mori S, Nakamura Y, Ogasawara H, Yazawa C, Nakatsuru S, Nose M (2000) Genetic dissection of vasculitis in MRL/lpr lupus mice: a novel susceptibility locus involving the CD72c allele. Eur J Immunol 30:2027-2037

Ravetch JV, Lanier LL (2000) Immune inhibitory receptors. Science 290:84-89

Sigurdsson S, Nordmark G, Göring HHH, Lindroos K, Wiman A-C, Sturfelt G, Jönsen A, Rantapää-Dahlqvist S, Möller B, Kere J, Koskenmies S, Widén E, Eloranta M-L, Julkunen H, Kristjansdottir H, Steinsson K, Alm G, Rönnblom L, Syvänen A-C (2005) Polymorphisms in the tyrosine kinase 2 and interferon regulatory factor 5 genes are associated with systemic lupus erythematosus. Am J Hum Genet 76:528-537

Simons K, Ikonen E (1997) Functional rafts in cell membranes. Nature 387:569-572

Siriboonrit U, Tsuchiya N, Sirikong M, Kyogoku C, Bejrachandra S, Suthipinittharm P, Luangtrakool K, Srinak D, Thongpradit R, Fujiwara K, Chandanayingyong D, Tokunaga K (2003) Association of Fc $\gamma$ receptor IIb and IIIb polymorphisms with susceptibility to systemic lupus erythematosus in Thais. Tissue Antigens 61:374-383

Su K, Wu J, Edberg JC, McKenzie SE, Kimberly RP (2002) Genomic organization of classical human low-affinity Fc $\gamma$ receptor genes. Genes Immun 3(Suppl 1):S51-S56

Su K, Wu J, Edberg JC, Li X, Ferguson P, Cooper GS, Langefeld CD, Kimberly RP (2004a) A promoter haplotype of the immunoreceptor tyrosine-based inhibitory motif-bearing Fc $\gamma$ RIIb alters receptor expression and associates with autoimmunity. I. Regulatory FCGR2B polymorphisms and their association with systemic lupus erythematosus. J Immunol 172:7186-7191

Su K, Li X, Edberg JC, Wu J, Ferguson P, Kimberly RP (2004b) A promoter haplotype of the immunoreceptor tyrosinebased inhibitory motif-bearing $\mathrm{Fc} \gamma \mathrm{RIIb}$ alters receptor expression and associates with autoimmunity. II. Differential binding of GATA4 and Yin-Yang1 transcription factors and correlated receptor expression and function. J Immunol 172:7192-7199

Suzuki T, Kono H, Hirose N, Okada M, Yamamoto T, Yamamoto K, Honda Z (2000) Differential involvement of Src family kinases in $\mathrm{Fc} \gamma$ receptor-mediated phagocytosis. J Immunol 165:473-482

Takai T (2002) Roles of Fc receptors in autoimmunity. Nat Rev Immunol 2:580-592 
Tsao BP (2004) Update on human systemic lupus erythematosus genetics. Curr Opin Rheumatol 16:513-521

Tsuchiya N, Kyogoku C (2005) Role of Fcy receptor IIb polymorphism in the genetic background of systemic lupus erythematosus: insights from Asia. Autoimmunity 38:347352

Tsuchiya N, Ohashi J, Tokunaga K (2002) Variations in immune response genes and their associations with multifactorial immune disorders. Immunol Rev 190:169-181
Yajima K, Nakamura A, Sugahara A, Takai T (2003) Fc $\gamma$ RIIB deficiency with Fas mutation is sufficient for the development of systemic autoimmune disease. Eur J Immunol 33:1020-1029

Yuasa T, Kubo S, Yoshino T, Ujike A, Matsumura K, Ono M, Ravetch JV, Takai T (1999) Deletion of Fc $\gamma$ receptor IIB renders $\mathrm{H}-2^{\mathrm{b}}$ mice susceptible to collagen-induced arthritis. J Exp Med 189:187-194 